\title{
Bim technology in the educational process
}

\author{
Alexandra Yakshina*, Galina Vasilovskaya, Maria Berseneva, Elena Danilovich and \\ Oksana Hoffman
}

Siberian Federal University, 660041, Krasnoyarsk, Svobodny Pr., 79, Russia

\begin{abstract}
In this article we discuss about the main trends by using BIMtechnologies in construction in the Russian Federation, possibilities of applying them in construction quality management and in staff training. Weoutlinethenecessity to improve the system of preparation and implementation of BIM-technologies in the new civil engineers educational process within the strategic development of the construction industry because it's very important for the further development of construction, architecture and other engineering areas. Here we analyze the possibilities of using BIM-technology in education programs for students of various specialties in the absence of real skills to create drawings on the example of the University of Architecture and Civil Engineering.
\end{abstract}

\section{Introduction}

In the Russian Federation in the second quarter of 2021 for state bodies and state corporations a legislative duty will be introduced to independently carry out the design of buildings and structures, as well as to purchase relevant works and services for the creation of construction objects only on the basis of BIM technologies. Until the end of 2022, all government agencies will carry out the construction of buildings and structures using digital modeling technologies. Thus, the transition of construction organizations to BIM is inevitable, and for future civil engineers, obtaining skills and abilities in this area is an urgent need $[1,2,3,4]$.

Information modeling of construction sites was first formed in the second half of the last century to create a common design space in real time and reduce the time spent on design. Over time, BIM technology has evolved and today digital modeling is used throughout the entire project life cycle.

BIM - Building Information Modeling. This technology is based on the collection and processing of comprehensive information about the object being built - architectural, technological, economic, environmental, operational and other characteristics. Based on this information, a 3D model of the future building is created [5,6,7].

The economic expediency of each stage of the life cycle is a mandatory indicator of the viability of the investment and construction project. Information modeling technologies make it possible to evaluate the effectiveness of the longest and most important stage operation $[8,9]$.

Today, for construction universities, the issue of training personnel with BIM - thinking

\footnotetext{
* Corresponding author: sestrasha@mail.ru
} 
in the design, construction and operation of facilities is relevant.

The description of the detail level of the BIM model for each stage of work on the project will make it possible to perceive the construction object as a whole one. Changing one of its parameters will inevitably entail an automatic change of the other parameters and objects associated with it [10].

\section{Methods}

BIM is an information platform on which you can impose additional technologies and capabilities with reference to the designed structure. The purpose of the proposed methodology based on BIM technology is to unify the approach to the process of automation of investment and construction projects (ICP) and to determine a unified structural approach to the use of three-dimensional modeling technology in the process of forming an integrated 3D model and a planned SMR model for training and practical application. BIM was created, among other things, so that design institutes, together with customers, at the initial design stage could work out any number of options and choose the best one. And at the same time to build an object at an adequate cost, with a clearly justified project documentation $[11,12,13,14,15,16]$.

The project, executed in BIM, is an interactive 3D-model, which without special difficulties combines the architectural, constructive, technological, estimated parts of the project with issues of engineering, transport infrastructure, logistics, etc. BIM affects not only construction, but everything that is relevant to it, considering the whole range of issues. BIM technology makes it possible to identify inconsistencies between sections and subsections of a project even at the initial stage of work and safely remove them. Due to this, both the construction and the further operation of the facility are also greatly simplified. Thus, the builders start the construction of the object, having in their hands a project that excludes minor production conflicts, which often impede the construction process $[17,18,19,20,21]$.

The widespread introduction of BIM technologies necessitates the training of specialists in the use of BIM technologies with modern information and communication technologies. The priority task of construction universities at this stage is the implementation of educational programs for the training and advanced training of specialists in BIMtechnologies.

For the training of specialists of a new type who possess BIM technologies of teamwork, an international project "Worldwide Initiative CDIO" (Conceive-DesignImplement-Operate) has been created, the basic principle of which is training engineers for a deep understanding, design, implementation and management of complex engineering projects in a team work . Currently, the project is being implemented in more than 100 engineering universities in 25 countries of the world.

Technologies of information modeling of industrial and civil construction include 3 cycles (table 1).

Table 1. Information modeling technology cycles of objects construction

\begin{tabular}{|l|l|l|}
\hline \multicolumn{1}{|c|}{ Development (Design) } & Construction (Build) & Operation (Operate) \\
\hline $\begin{array}{l}\text { - conceptual design, } \\
\text { - detailed design, } \\
\text { - analysis and calculations, } \\
\text { - documentation. }\end{array}$ & $\begin{array}{l}\text { - preparation, } \\
\text { - building works, }\end{array}$ & - operation \\
\hline
\end{tabular}


Preparation of bachelors for teamwork is a prerequisite for effective work on common information models, and the realization of the work is based on the implementation of the main stages and is possible regardless of the location of each of them. (figure 1).

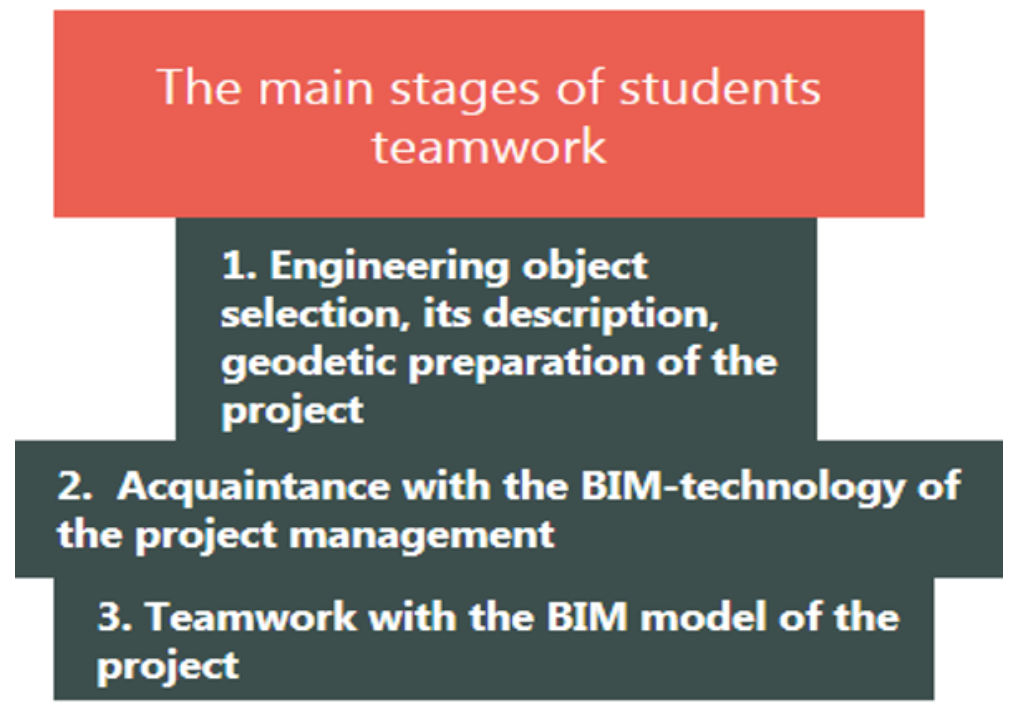

Fig.1. The main stages of students teamwork

This technique allows students to acquire design skills using information modeling technology that contains information being used further in constructive calculations, energy efficiency assessment, determination of technical and economic indicators, costing, specifications, etc.

Within the framework of the CDIO concept, 12 standards were developed, which are the basis for the reform and assessment of the quality of educational programs (table 2).

Table 2. CDIO standards groups

\begin{tabular}{|l|}
\hline 1 - engineering program concept \\
\hline $2,3,4$ - curriculum requirements; \\
\hline 5,6 - educational environment requirements; \\
\hline 7,8 - teaching methods; \\
\hline 9,10 - professors qualifications; \\
\hline 11,12 - assessment methods of learning results. \\
\hline
\end{tabular}

There are also some standards for requirements for the organization of working space and material and technical provision for the classrooms to prepare students for engineering activities.

Working space zones of the auditorium:

- a zone for discussing a project idea and developing a technical task in a team with all possible and accessible information resources;

- design zone - allowing to develop a project, carry out the necessary calculations, equipped with computer and software for BIM modeling;

- project implementation area - allows you to organize the creation of a prototype of the designed object, for example, using a 3D printer; 
- a trial area designed for testing a 3D model, to evaluate the performance of an object, and compare it with calculated values.

Graduates trained in this educational program will be able to perform several types of professional activities in the future:

- engineering services at the stage of pre-project works;

- design(project) and technological engineering:

- software and technical support, development of schedules for construction processes with high detalization level;

- management of buildings' life cycles, the construction and application of information models of objects and processes;

- organizational project management

- electrical and installation work at the construction site.

In the present, it became possible to hold discussions within the computational models themselves, where participants perform under their "avatars", not being in the same room to discuss design issues from completely new points of view, moving from two-dimensional images to a modern virtual environment.

Combining real-time project information significantly reduces project risks by minimizing the time between different stages of decision making, as well as between receiving and using information. With a large number of project participants having access to project information, cooperation in real-time mode reduces the likelihood of the parties using irrelevant information. It is also important that such an approach avoids a significant part of the risks, firstly, by providing the necessary information in a timely manner and, secondly, through a more rapid process of entering new information and revising the design decisions.

\section{Results}

The speed of preparing people for digital technology is beginning to lag both around the world and in Russia. Future civil engineers will face a number of problems, possible solutions to some of them can be identified at the training stage.

A common and very serious mistake is the inconsistency of the draft with the requirements of technical regulations in matters of security. Assuming the fact that the design substantiation of the design decisions made in the project could be not presented or there is no confirmation of the preservation of structures and utilities that fall into the construction zone. The design of fire protection systems is also often done with a deviation from the requirements of technical regulations and fire safety standards. This is a huge mistake - the operation of the facility, built according to such documentation, will be simply unsafe.

The complexity of teaching without the use of modern computer technology is obvious: there are no mockups for each specific task, nor are there any illustrations that allow us to review and evaluate the solution from all sides. Drawing the solution of the problem on the board is not visual, but the reproduction of the trainees using drawing tools on paper in the limited time mode and insufficient preparation is sometimes disastrously useless. A modern student who has chosen a specialty as a civil engineer or architect sometimes does not understand the specifics of these professions. Many of them were not trained in drafting school, and, therefore, do not even have the basic drawing skills.

In accordance with the modern requirements of design, students today are needed to be given the opportunity to create a single multi-dimensional space.

Currently, BIM is used in the construction of private housing and in the private sector. Some industry companies launch their industry standards, so the problem of using BIM 
technologies is solved locally - within the industry. But in general, in the construction industry in the country, everything is much more complicated. First of all, the high costs required for the introduction of a new technology hamper the development of BIM in Russia. They are expressed not only in the financial costs of purchasing new software, updating personal computers, but also in the need to train employees, adapt all work processes and the entire team of the company to new requirements and new business processes.

Unfortunately, the domestic software product cannot yet compete with Western technologies. For Russian companies it is often a problem that initially BIM is a foreign technology, which means that they need to adapt standards to Russian norms.

The modern pace of construction overtakes the pace of design, and the actualization of design solutions is on the verge of the construction work itself. This leads to the fact that it is impossible to work normally with models, and you have to go back to the old analytical methods, where the probability of error increases.

Photogrammetry can be used for dismantling and construction objects. However, the process of this method for modeling unsystematic processes or building objects by capturing can be quite labor-intensive. To solve this issue, the best option is to take a stepby-step survey, that is, entering the field and making a slice, for example, in two weeks, or in a month - to verify the actual state with the model, which is a bit difficult in the existing training framework.

The progress of construction and installation work, the backlog or advance of the schedule, the ratio of stages of construction with costs - this information is most important for making accurate and timely management decisions. The information model with the schedule becomes an excellent tool for managing the stage of construction and installation works. Such an information model serves as an assistant in the planning of work for all performers. Since BIM technology is the process of accumulating information, the opportunity it provides is a quality control system. The technology allows to accumulate information in the model about the property not only in terms of project documentation, but also in the executive. Accurate coordination of tasks, quick and accurate determination of the scope of work, coordination with equipment suppliers when ordering materials and other monitoring of occupational safety and health. At the same time, the ability to influence the cost of the project decreases as the building is erected.

One of the duties of the engineer (specialist) in labor protection, which is associated with repair or construction works, is the approval of the COP (construction organization project), WPP (works' production project), CWPP (cranes work production project), TM (technological maps). Such duties are not only part of the labor protection engineer's work, but also part of the systematic organization of the construction industry. A comprehensive assessment of occupational safety in a construction organization allows modern information technologies to be implemented, combining a set of regulatory documentation on occupational safety at the construction site, with BIM- model of the test area.

The basis of this approach is to assess the level of occupational safety and health in construction organizations with the use of BIM technology is the prevention of accidents at the inspected object, the reduction of injuries and the level of occupational diseases.

The main stages of assessing the state of labor protection and safety at a construction site include:

- Identification of hazardous factors with the determination of their quantitative and qualitative characteristics;

- analysis of hazardous and harmful production factors affecting the construction site personnel regarding the type of work performed;

- assessment of the risk of displaying of the identified hazardous and harmful factors on the production personnel of the construction site 
- risk classification based on current regulatory documents;

- determination of values of acceptable risk affecting the personnel at the construction object.

Using BIM modeling in training can be especially useful for buildings that have already been built, where it can be especially difficult to understand something from the plans, since they often consist of several structures and extensions.

When using BIM and rich model data as a tool to support design review and process safety analysis, violations can be automatically identified by applying predefined rules based on the categorization of components to identify areas of potential risk.

Construction can be done twice; once in a virtual environment where errors and various solutions can be made, comparing already conducted in a real environment where 4D BIM is used, which includes time as a parameter, existing risks and progress that has been completed so far, can be assessed for different stages of the project life cycle.

Experience shows that the benefits of BIM in the planning phase include:

- Design solutions can be configured and evaluated without putting students at risk.

- You can compare the benefits, risks and costs of different solutions.

- Trainees can understand the project and its requirements better and can plan the future more effectively.

- 3D visualization allows you to identify problems at an early stage of the project.

- Collisions can be eliminated or softened quickly, reducing the risk at the place.

- The model facilitates teamwork and accelerates decision-making.

- Future civil engineers can get a more complete picture of the project and the intended work order.

- Trainees can contribute to improve the project plan and reduce risk.

- The viability of equipment, facilities and infrastructure can be tested outside the working process.

- Constructed or installation sequences can be modeled and evaluated in terms of viability.

- You can identify potential problems and take action to eliminate or mitigate them.

- BIM objects can be used for on-site security and logistics planning.

According to statistics, the number of foreign citizens from CIS countries operating in the Russian Federation is more than $76 \%$, while $18 \%$ have work permits and $41 \%$ of them are in the age group of 18-29 years. The construction industry takes the 4 th place or $8.4 \%$ in the number of employed labor resources after trade, manufacturing and services, in which up to $20 \%$ of labor resources are attracted from the CIS countries. At the same time, industrial injuries show that in 2015 there were 217 deaths in the construction of buildings and structures. According to the Social Security Fund, construction is the second type of economic activity (after the manufacturing industry) for injury risk. When investigating accidents, there are often deficiencies in training or ignorance by workers of labor protection requirements, the absence of any technological documentation. All this creates not only the risk of increasing the time and cost of construction, but also the most important thing - human life.

BIM-technology acts as a kind of information platform on which it is possible to impose new software products, for example, conducting an injury risk assessment.

\section{Discussion}

Currently, the global construction industry is going through a transformation process associated with the abandonment of traditional design and construction methods in favor of innovative ways to implement projects. 
Examples of the implementation of investment and construction projects of varying complexity around the world have shown the high efficiency of the integrated application of information modeling technology. A reduction in the terms of design and construction, a reduction in the project budget, a more accurate estimate of the cost of construction, effective interaction and exchange of information between all project participants were noted. This has led to an increase in the economic efficiency of the company using BIM technologies (figure 2).

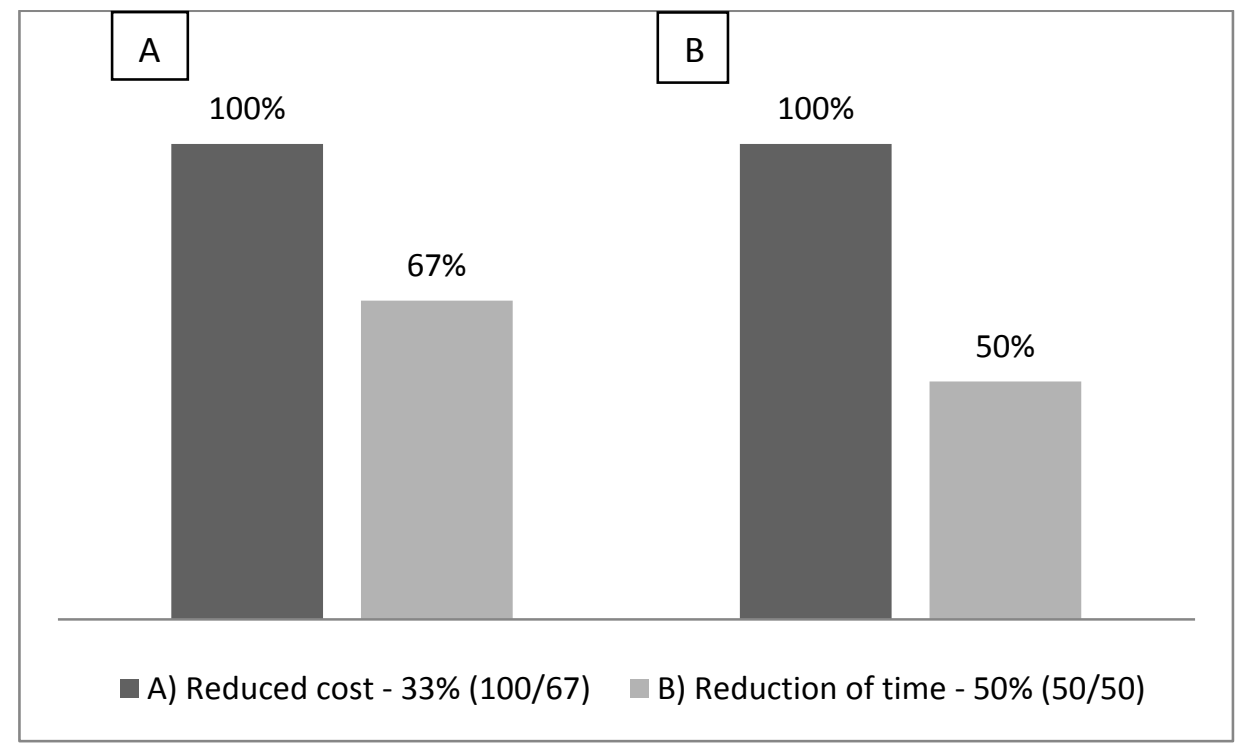

Fig.2. Expected Benefits of BIM Technologies

The high level of implementation of BIM technologies in the construction industry has been noted in the USA, and a number of developed countries in Europe and Asia are explained by government support.

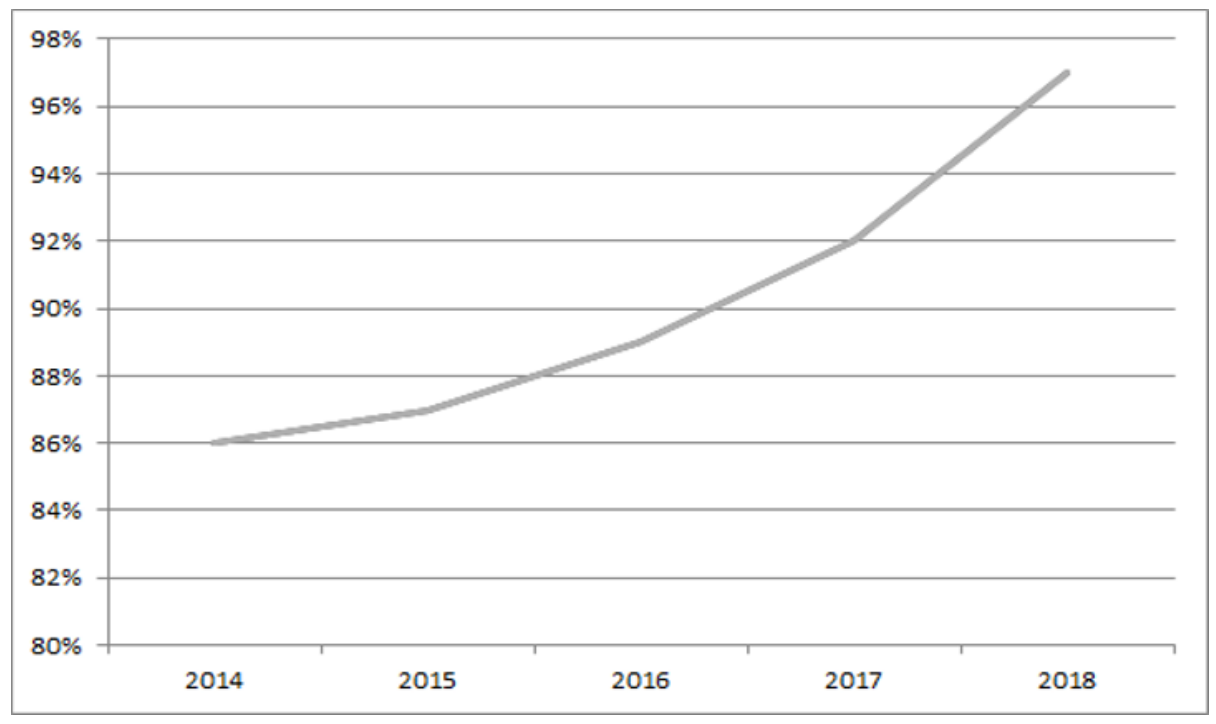

Fig.3. The use of BIM technology in the United States and developed countries 
Currently, the implementation of BIM technologies in Russia is at an early stage. The need and need for the speedy development of BIM-technologies is recognized at the state level.

In December 2014, the Ministry of Construction and Housing and Communal Services of the Russian Federation approved a plan for the phased introduction of information modeling technologies in the field of industrial and civil construction.

In 2015, pilot projects were selected, the design of which was carried out using BIM technologies.

In 2016, changes were made to the regulatory and technical regulations and educational standards, new standards and codes were developed to ensure the applicability of projects implemented using BIM technologies.

Since 2017, financing from the budgets of the Russian Federation at various levels has been provided for certain categories (types) of orders for design work and construction contracts made using BIM technologies.

Today, all innovative Russian enterprises are actively introducing BIM-technologies, the use of which allowed the creation of such significant objects as the high-rise building of MIBC Moscow-City, the second stage of the Mariinsky Theater in St. Petersburg, the Olympic stadium Fisht, the Bolshoi Ice Palaces ", “ Iceberg ”, indoor speed skating center" Adler-Arena "in the city of Sochi and many others.

The task of the construction universities of Russia is to train specialists in various fields in the use of information modeling technologies in the field of industrial and civil construction. Bachelors are being trained in the direction of 08.03.01 "Construction", taking into account the requirements of the construction industry market for future engineering and technical personnel.

In frames of the study such disciplines as "Engineering Graphics", "Computer Graphics in Design," students perform plane architectural and construction drawings in accordance with the applicable standards.

While studying the disciplines "Architecture of Civil and Industrial Buildings and Structures", "Information Technologies in Construction", students acquire skills in AutodeskRevitArchitecture, allowing to perform design from creating a conceptual model of a building to issuing working documentation of the architectural and construction part of the project.

\section{Conclusions}

The importance of BIM - technology for the further development of construction, architecture and other engineering areas should be definitely noted. While training the personnel the following conclusions might be done:

- the possibility of using BIM - technology at all stages of the project life cycle: design, construction and operation of the object, allows the student to consider the object in detail at each stage;

- also BIM - technologies allow to see the object in a complex;

- develops the ability to work in a team, while knowing the result of private decisions made;

- information model allows to significantly expand the range of studied objects.

The consequence of these skills makes it possible to predict and evaluate energyefficient indicators, to carry out and analyze technical and economic calculations, to generate accounting documents at a more modern level.

Opportunities for graduates in this field may not be limited to one and only type of professional activity. It has the ability to combine architectural, structural and technological solutions, the estimated parts of the project with engineering, transport infrastructure, 
logistics and utilities in one logical chain. To see at the design stage unreasonable design decisions, inconsistencies between sections and to identify a causal relationship.

The absence of a territorial framework makes it possible to obtain information from anywhere in the world.

Timely updating of design solutions improves not only the quality of education, but also the professional qualities of a specialist at the exit.

The ability to simulate a force majeure situation allows you to minimize risks and improve safety in the industry.

Thanks to technological advances and the proliferation of building information modeling (BIM) technology, new opportunities are emerging for improving learning processes. Due to the complex interaction between traditional training programs and BIM software packages, many of the advantages of BIM technology remain unclaimed. The undeniable advantages are the use of data stored in the information model, their integration with the data of already implemented projects, the use of modern software will reduce the time and improve the quality of education in training for the construction industry.

\section{References}

1. Using BIM Structured Information to Protect Health and Safety of Workers in Construction Alenkov V.V., Kupriyanovskiy V.P., Shaklein A.G., Ovsyannikov M.L., Chebotarev E.M., Yartsev D.I., Kolesnikov A.N. International Journal of Open Information Technologies. 2018. Vol. 6. No. 5. P. 39-50.

2. Autodesk revit - highly qualified civil engineers Zolotova J., Vatin N., Tuchkevich E., Rechinsky A., Tuchkevich V. Applied Mechanics and Materials. 2015. T. 725-726. Pp. 1617-1625.

3. Methodology for assessing safety achievement factors at a construction site based on information modeling Sharmanov V.V. Academic bulletin UralNIIproekt RAACS. 2017. № 3 (34). Pp. 72-79.

4. Features BIM. Experience of using BIM in Russia Zhakhina UA, Epifantseva L.R. In the collection: New Technologies for the Oil and Gas Region. Materials of the International Scientific and Practical Conference. Executive editor P.V. Evtin. 2018. pp. 175-177.

5. BIM, new interaction standards open Pastukhova Ya.Z. Scientific Review. 2015. No. 13. S. 155-158.

6. BIM technologies, BIM technologies, without which construction cannot live! Korolev A.V. Construction: new technologies - new equipment. 2016. No. 1. P. 20-22.

7. Pre-construction stage based on bim Li M., Yu H., Liu P. Automation in Construction. 2018. T. 91. p. 284-292.

8. Russian experience of using BIM in architecture and urban planning Poluektov V.V. In the collection: Modern technologies and techniques in the architectural and artistic education materials of the international scientific methodical conference. 2016. pp. 179181.

9. Implementation of building information modeling (BIM) Ganiev A.A. In the book: Science in Progress theses of the All-Russian scientific-practical conference of undergraduates and graduate students. 2016. pp. 55-56.

10. The main stages of the introduction of information modeling technology (BIM) in construction organizations Solovyova E.V., Selvian M.A. Scientific works of the Kuban State Technological University. 2016. No. 11. P. 110-119. 
11. BIM in off-site manufacturing for buildings Abanda F.H., Tah J.H.M., Cheung F.K.T. Journal of Building Engineering. 2017. V. 14. S. 89-102. Engineering and Construction Journal. 2017. No. 1 (69). Pp. 77-88.

12. Lean construction and BIM: complementing each other for better project management Eroshkin S. Y., Kallaur G. Y., Papikian L. M. // Review of business and economics studies. 2016. No. 4. P. 17-22.

13. The use of BIM-technologies in the tasks of quality control and labor protection Cherkina V.M., Evich A.A. In the collection: Integration, partnership and innovations in construction science and education, a collection of materials of an international scientific conference. FSBEI of HE "National Research Moscow State University of Civil Engineering". 2017. p. 382-385.

14. BIM-modeling in construction and architecture Materials of the All-Russian scientificpractical conference / 2018.

15. A review of BIM capabilities for quantity surveying practice Ismail N.A.A., Drogemuller R., Owen R., Beazley S. In the collection: MATEC Web of Conferences 2016. p. 00042.

16. BIM-technology in tasks of the designing complex systems of alternative energy supply Volkov A.A., Sukneva L.V. Procedia Engineering 2014. T. 91. C. 377-380.

17. The International Paradigm of Life-Saving Railway Life Cycle Standardization // International Journal of Open Information Technologies. Kupriyanovsky V. et al. international journal of open information technologies -T. 5. No. 2. 2017-C. 64-84.

18. Non-destructive approach for the generation and thermal character of as-built BIM Lagüela S., Díaz-Vilariño L., Armesto J., Arias P. Construction and Building Materials. 2014. T. 51. p. 55-61

19. BIM in the assessment of labor protection Sharmanov V.V., Simankina T.L., Mamaev A.E. Engineering and Construction Journal. 2017. No. 1 (69). Pp. 77-88.

20. Non-destructive approach for the generation and thermal character of as-built BIM Lagüela S., Díaz-Vilariño L., Armesto J., Arias P. Construction and Building Materials. 2014. T. 51. p. 55-61.

21. Features of BIM implementation using autodesk software Vysotskiy A., Makarov S., Zolotova Ju., Tuchkevich E. Procedia Engineering. 2015. T. 117. S. 1143-1152. 